\title{
6 Use of evidence in a complex social programme
}

\author{
Case of an evaluation of the \\ state's response to violence \\ against women and children \\ in South Africa
}

\author{
Matodzi M.Amisi, Thabani Buthelezi \\ and Siza Magangoe
}

\section{Summary}

This chapter focuses on the use of evidence from the Diagnostic Review of South Africa's response to violence against women and children (VAWC), carried out by the Department of Planning, Monitoring and Evaluation and Department of Social Development between 2014 and 2016. The Diagnostic Review provided evidence that government needed to develop a new plan for VAWC, increase the budget allocation for violence prevention and services and better coordinate VAWC responses, all of which is being taken forward in the National Strategic Plan for gender-based violence. Many of the interventions to promote the use of evaluations come from the national evaluation system, such as evaluation steering committees and improvement plans. These were found to have created ownership and likely use. The interventions were optimised through strong knowledge brokering by government evaluation units and creation of spaces for intersectoral dialogue to facilitate evidence use. The chapter adds to the knowledge base of factors that facilitate or inhibit evidence use in multi-sectoral complex interventions.

\section{Introduction}

Women and children in South Africa experience a very high level of different forms of violence including intimate partner violence, neglect, rape, femicide, child homicide and sexual assault. Research undertaken by South Africa's Medical Research Council reveals that $25 \%$ of women have experienced physical violence at some point in their lives (Gender Links and The Medical Research Council. 2010). Violence against children (VAC) shows the same trends, with studies finding that 1 in 3 children in South Africa have experienced some form of violence (Ward et al., 2018).

These high levels of violence have persisted despite significant investment by government, development partners, and civil society organisations (CSOs) in evidence generation, enacting policy, setting up institutions, allocating resources 
and delivering services aimed at reducing violence. This chapter uses the journey of the Diagnostic Review of South Africa's response to violence against women and children (VAWC) to understand facilitators and barriers to evidence use in public policy. The Diagnostic Review was carried out between 2014 and 2016 by South Africa's Departments of Planning Monitoring and Evaluation (DPME) and Social Development (DSD). The chapter also provides a snapshot of the operations of South Africa's national evaluation system (NES), in itself an important policy experiment in promoting the generation and use of evaluation evidence. Lessons shared in the chapter should improve uptake of research evidence in the VAWC sector in South Africa and offer insight and suggestions for improving uptake of evidence in other multi-sectoral interventions to address complex social problems.

The chapter draws from a case study carried out as part of a research project titled Evidence in Practice: Documenting and Sharing Lessons from EvidenceInformed Policy Making and Implementation in Africa. Data for the case study was collected between November 2018 and March 2019. The data comes from semi-structured interviews with 14 key informants, document review and participant observation. The main author was the evaluation lead from DPME on this project; the second author was chief of monitoring and evaluation (M\&E) in DSD at the time the evaluation was done; and the third author led the policy process. Respondents were selected purposively because of their knowledge of the sector and known active participation in relevant policy and programme delivery. The case study used the framework described in Chapter 3 to guide data collection and analysis. In addition, the case applied the realist notion of change (outcomes) being the result of interaction between context and mechanism. Thus, the case study aimed to understand which evidence use interventions worked to produce which outcomes (decision/policy) and in which context.

\section{Background: country, institutional and policy context}

South Africa's democracy is nascent, established only in 1994 after many years of struggle against white minority rule. While the country has made significant investment in social protection, human development outcomes have not improved at the rate anticipated, partly due to social problems such as high levels of violence, decades of under-investment in human capital, poor nutrition and so forth. This has contributed to high levels of unemployment and underdevelopment. Seventy-six percent of the population, mostly black South Africans, live with the constant threat of poverty (World Bank, 2018). Family and household structures have also been strongly shaped by apartheid's restrictive labour migration policies which forced separation of migrant men from their families. While these policies were relaxed in the early 1990s and completely abolished after 1994, the result is that nuclear families are not the norm in South Africa, which impacts family dynamics and the ability of families to protect children. In fact, couples living with their own children make up only $19 \%$ of all households and $62 \%$ of children live in extended family arrangements (Hall and Mokomane, 2018, pp. 31-32), with single parent households representing $11 \%$ of households. 
Though the constitution and government legislation are considered progressive, societal values are conservative. The 2016 Community Survey reports that more than $80 \%$ of the South African population is religious, with about $78 \%$ professing to be Christian, $4 \%$ practicing African religions and $2.6 \%$ being Muslim or Hindu (Statistics South Africa, 2016, p. 42). Patriarchy is embedded in the traditions, customs and values of most African cultures, and during apartheid it was state sanctioned, with white men having most rights and black women least rights and protection (Meer, 2016;Ademiluka, 2018). Others have argued that it is this confluence of deeply embedded patriarchy, religious conservatism, inequality, poverty, breakdown of the family and history of statesanctioned violence under apartheid that has left South Africa battling with high levels of untreated trauma that is reproducing violence. The complexity makes responding to the problem so difficult (Lamb and Warton, 2011).

An important factor in South Africa's response to violence is government's configuration and capacity. The democratic political system of government at national, provincial and local level is a result of the 1994 consolidation of the apartheid state's racially fragmented administrations. Constitutional instructions allocate public service functions as either the exclusive mandate of national, provincial or local government or shared between spheres of government. Provincial and local governments are independent spheres of government and can determine their own priorities, develop plans and implement programmes (Amisi andVawda, 2017), and they have varying capacity and resources (Chipkin and Meny-Gibert, 2011). This fragmentation diminishes government's ability to collaborate and deliver integrated services. This problem is experienced in government response to VAWC. For example, though most departments have done relatively well in delivering on their respective VAWC mandates, they have not effectively collaborated to optimise their cumulative effect enough to reduce the levels and effect of violence (DPME and DSD, 2016; Gould et al., 2019).

South Africa has a vibrant NGO sector and NGOs are critical to the country's response to VAWC. Nearly $40 \%$ of all registered NGOs operate in the social services sector (DPME and DSD, 2017). More than 90\% of social welfare services, includingVAWC services, are provided by NGOs (Barberton et al., 2018, quoted in Gould et al., 2019). Analysis done by National Treasury shows that government funding for social welfare services is low and NPOs experience up to a $71 \%$ funding gap (Barberton et al., 2018, p. i). In relation to NGOs, government is a policy maker, a regulator, a funder and, in some cases, a co-provider of services. The interplay of these different roles and funding challenges have caused conflict in the sector (DPME and DSD, 2017; Barberton et al., 2018) which also influences the flow of information between the government and CSOs.

\section{The evolution of VAWC-related national policies}

Over the years, the national policy landscape relating to VAWC has changed rapidly, reflecting a shift in paradigm and political leadership in the different ministries and the country. Figure 6.1 provides a visual representation of the policy timeline briefly introduced in preceding sections. 


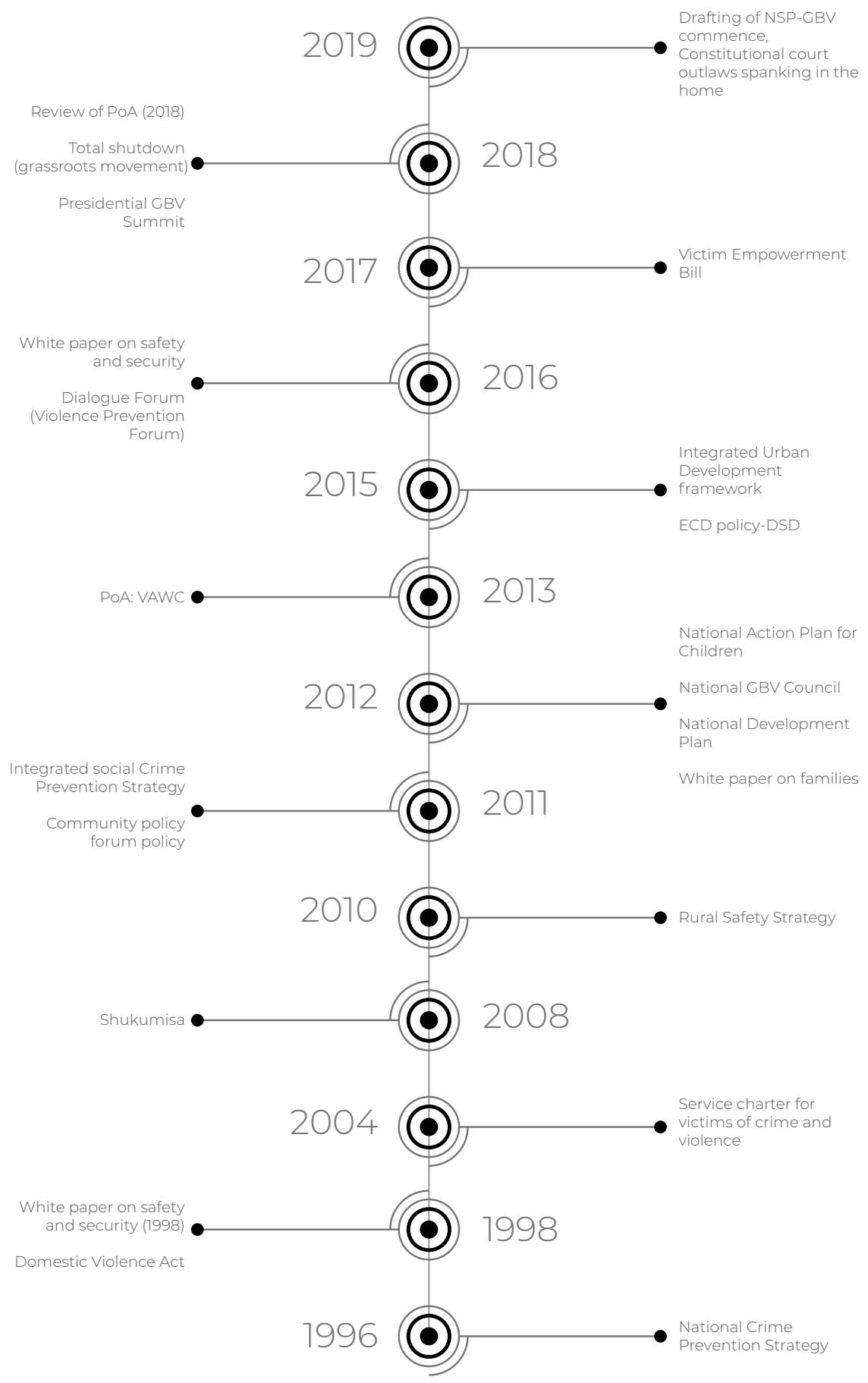

Figure 6.1 Timeline showing the evolution of VAWC-related national policy Source:Author generated. 
Though the timeline depicts a linear evolution of policy, in practice this has not been the case and it has been punctuated by changes in political leadership which, in most cases, have led to changes in policy direction. For example, Rauch (2000) argues that the shift in focus from crime prevention in the National Crime Prevention Strategy to crime combating was precipitated by a change in minister. One of the striking aspects of policy relating to VAWC is the difference in how criminal justice departments and social sector departments understand and respond to VAWC. Social sector departments are likely to see VAWC as a social problem that requires socio-economic interventions while criminal justice departments are likely to take a tough-on-crime approach (DPME and DSD, 2016). Attempts to address this policy disjuncture include the development of the Integrated Social Crime Prevention Strategy in 2011, led by DSD. More recently, the inter-ministerial committee (IMC) on VAWC, the Programme of Action on Violence against Women and Children (PoA:VAWC) and the White Paper on Safety and Security 2016 cover programmes from both criminal justice and social sector departments.

\section{Identifying the need for evidence}

A key element of the analytical framework on evidence use presented in Chapter 3 is the demand for evidence.This section explores the sources of the demand for evidence.

When the IMC on VAWC was established in 2010, it was tasked with investigating the root causes of VAWC and how to end all forms of violence against women and children. The South African government has a culture of commissioning evidence and so it was not surprising that when the IMC was established, they commissioned two studies to guide their work. One of the studies came to be known as the Diagnostic Review. DSD's evaluation unit recommended that the review be carried out as part of the National Evaluation Plan (NEP) implemented by the DPME and governed by South Africa's National Evaluation Policy Framework (NEPF). DPME's involvement would help because the evaluation required involvement of multiple departments. Secondly, the NEPF would ensure that the Diagnostic Review would be taken to Cabinet. Both the Evaluation and Policy Units in DSD viewed submission to Cabinet as a potential trigger for change, as Cabinet has the power to give direction/instructions to departments.

The Diagnostic Review was carried out at the demand of the potential evidence users in the IMC to answer an existing policy question, and with the participation of policy makers so they could be part of shaping the research process. Data from the interviews indicates this is not always the case for research in the sector. One respondent stated, 'there is almost an attitude amongst researchers, it is research for research sake, whether it finds practical application in government they do not seem to really care' (Respondent 8 - development partner). Another respondent said,

I have been looking a lot at evidence on what work [is needed] to prevent VAWC.... The information is not helpful for implementers. The questions about costs, transferability, etc. are not answered. Without intending to do so, researchers fail policy makers because we don't answer the right questions.

(Respondent 4 - think tank) 
The role of development partners was important in the demand for evidence. Both the root cause analysis study and the Diagnostic Review were funded by UNICEF. This gave UNICEF some power in shaping the conceptualisation and use of the two studies, as we will show in the next sections.

\section{The evaluation process}

The NEPF directs all national evaluations to be managed by a technical working group (TWG) and evaluation steering committee (ESC). The TWG included DSD and UNICEF. The TWG developed the terms of reference (ToRs) and managed the evaluation, while the ESC, headed by the senior policy head from DSD oversaw the evaluation. For the Diagnostic Review, the technical committee for the IMC (IMC TTT) took on an additional role as the steering committee for the evaluation. Having these cross-government structures was important for the evaluation to incorporate what was happening in different subsectors and to have the support and ownership of the key departments.

It was difficult to attain consensus between the different departments on what the Diagnostic Review should cover, which showed unresolved policy dissonance in the sector.At the time of the evaluation, there were numerous discussions within the TWG and ESC (IMC TTT) about whether the problem is violence against women, gender-based violence (GBV) or violence against women and children. Framing the evaluation as responding to gender-based violence meant excluding violence against children, particularly forms of violence that are not gendered, such as spanking in the home, corporal punishment at schools and violence between children. The Children's Unit within DSD and UNICEF did not accept this proposal. The ESC did not approve separating women and children. Focusing on both VAW andVAC showed a recognition of the intersection between violence experienced by women and children. Thus, the decision about the evaluation focus was, in itself, signalling a policy position by government. The process to get consensus on the questions to be asked and the scope of the evaluation took some time; the ToRs went through 14 iterations from October 2013 to December 2013 before final approval by the ESC. The ability to broker a safe space for consensus building was an important role of the ESC.

The evaluation process was guided by the ESC. They substantively shaped the research process and the recommendations and approved the final report. This resulted in departments owning the recommendations but also the recommendations addressing key gaps in how government was responding to VAWC. The Diagnostic Review did not generate anything radically new but, as one of the respondents indicated, 'The difference was that this was done by government, and government itself was acknowledging these issues' (Respondent 4 - think tank).

\section{Taking forward the findings}

Following approval of the final report by the steering committee, the head of the steering committee formulates a management response to the recommendations 
and oversees the drafting of an improvement plan which spells out steps that will be taken to address the recommendations. In the current case, the plan was developed in a workshop with CSOs, government departments and development partners. The improvement plan was approved in April 2017 by the IMC TTT and was submitted for formal ratification by the head of the IMC TTT (director general of DSD) in July 2017.

The Diagnostic Review's findings were translated to messages for different target audiences. DPME, working together with DSD's policy and evaluation units, translated the evaluation report and improvement plan into a seven-page cabinet memorandum. Only key findings and recommendations were carefully selected by DSD and DPME to be presented in the memorandum. The memorandum was presented to different coordinating structures of government; firstly the cluster of director generals and then tabled at a Cabinet sub-committee. Because of the cross-cutting nature of VAWC, the Diagnostic Review was presented to both the social cluster and the criminal justice cluster and their respective Cabinet committees.

This process was carefully managed, balancing both political and technical pressures. The process took a year, with disagreements between departments leading departments to ask DPME to give them more time to interrogate the report and recommendations to units within departments who did not participate in the ESC but were affected by the recommendations. The submission to Cabinet made sure that heads of departments in the social and criminal justice sectors and all ministers were aware of the important findings and recommendations in the Diagnostic Review and that they were accountable for implementing the improvement plan. As with discussions in the ESC, the submission process offered space for senior managers and ministers to debate how government can improve its response to the problem. Approval by Cabinet was also the mechanism that enabled wider dissemination of the report. Under the National Evaluation System, once a report is approved by Cabinet without reservation, it can be made public and sent to Parliament.

As required by the NEPF, significant efforts were made to share the results. All important documents were placed on DPME and DSD websites, including the full report, the management response to the recommendations from the DSD, the improvement plan, and reports on progress against the improvement plan. This made the report easy to access by the sector. It also made government transparent in its learning, important in a sector fraught with mistrust and conflictual relationships between different stakeholders.

Two policy briefs were developed informed by the evaluation, one co-authored by DPME and DSD's evaluation and policy units, and one with the Institute for Security Studies and Save the Children South Africa. This co-production of policy briefs was intended to improve ownership and wider dissemination of results. The findings were also presented by government officials in DPME and DSD in more than ten different workshops and seminars, which familiarised the sector with the findings and recommendations of the evaluation and the resultant improvement plan. This showed ownership by government of the 
findings and commitment to addressing the issues identified, addressing a challenge in the sector where researchers often speak of failure by state agencies to respond, leading to further divisions/conflicts.

Internal government M\&E units facilitated use of the Diagnostic Review through ongoing knowledge brokering within government and with external stakeholders. Within DSD the evaluation unit played an internal knowledge broker role, translating the research report into an internal communication memorandum to communicate to management of the department the findings and implications of the Diagnostic Review and the improvement plan. The unit also ensured that the minister was briefed before the presentation of the evaluation in Cabinet and the team presenting to Cabinet were aware of what is politically acceptable and what is not. DPME also played a strong knowledge broker role, working with DSD and other departments to make sure findings and lessons from the Diagnostic Review were integrated into the Programme of Action (PoA) on VAWC and its M\&E framework. DPME continues to play an important role in the National Strategic Plan for GBV.As shown in the following comments, this role was influential:

The respect given to DPME based on the pivotal role of the department and the mandate assigned to the department, and the level of work that the department did around the Diagnostic Review contributed to the buy in from departments. The push from DPME was very helpful. They did not come as big brother but gently guided the departments.

(Respondent 1 - development partner)

DPME is in the Presidency and this gave us some influence. It is the politics of being in the Presidency. The clout that came with being DPME, that is why we were able to enforce some of the work.

(Respondent 2 - government)

\section{Analysing use and the factors which contributed to use}

This book seeks to contribute to an understanding of how evidence use can be promoted. In this section, we therefore first seek to understand the types of use that happened in the Diagnostic Review, and then unpack how the different use interventions and other factors contributed to, or inhibited, use.

\section{Using the results of the Diagnostic Review}

There are different ways of understanding use, and Chapters 1 and 2 discuss instrumental, conceptual, symbolic and process use. Instrumental use refers to cases where the recommendations are implemented, while conceptual use refers to cases where information provided through the research gives new insight and understanding that shapes the ways individuals and organisations do their work. Very often, organisations which track use of evaluations track responses to individual recommendations (i.e. instrumental use). As this chapter 
will show, in multi-sectoral complex interventions, conceptual use can be an important enabler for wider policy changes and remains important in EIDM.

\section{Instrumental use of the Diagnostic Review}

The following are some instrumental uses of the Diagnostic Review:

1 The Review of the PoA was informed by the results of the Diagnostic Review In 2017, DSD with the support of UNICEF started a process to review and develop a new PoA. This responded to the first recommendation of the Diagnostic Review. Though this process was paused pending the completion of the National Strategic Plan, the Diagnostic Review and other research studies were important sources in the revision process and in the NSP, as shown in the comment:

The current PoA it is trying to embrace the evidence that was generated from the evaluation, the system-strengthening pillar was informed by the Diagnostic Review. The majority of issues [addressed in the PoA] came from there [Diagnostic Review], the coordination structure, the issue of information management, issue of social mobilisation.

(Respondent 1 - development partner)

2 Bringing the voice of CSOs and provincial government to the revision of the PoA

The revision of the PoA followed the process recommended by the Diagnostic Review, which emphasised the involvement of CSOs and provincial government. The ToRs advertised by UNICEF for a consultant to review the PoA specifically mentioned the need to consult with CSOs and provincial government in the review of the PoA. However, the way the involvement of CSOs was handled highlighted some limitations with tracking/measuring instrumental use of evaluation findings. DSD implemented several recommendations as articulated in the report, but without fully owning the intent underlying the recommendation. Therefore, the extent to which the implementation of the recommendation will change practice over time is not yet known.

3 Establishment of a coordinating structure forVAWC

The Diagnostic Review recommended that a structure be established to coordinate the work of multiple departments responding to VAWC and that this structure must include NGOs. This was included in the revised PoA and in the Victim Empowerment Bill (2017), and was supported by DSD in the process of developing the National Strategic Plan for GBV.

4 Increase in the budget allocation for violence prevention 
In 2018, National Treasury announced an additional budget allocation to provincial DSDs for VAWC programmes. The budget was increased by ZAR 206 million in the financial year 2018/19 while ZAR 309 million was added for the 2019/2020 financial year. This was a much-needed increase in strained budgets and addressed a big concern in the Review. The increase came as a result of a confluence of interventions. The Diagnostic Review found significant shortfalls in funding for response services. DSD used this finding in its budget proposal to National Treasury to motivate for additional budget allocation. However, this was only supported by National Treasury because other factors had influenced Treasury officials to believe that violence can be prevented, and that resources allocated for response services are inadequate, amongst others. This is shown in the next section.

\section{Conceptual use}

Respondents reported some cases of conceptual use. For example, UNICEF indicated that the evidence from the Diagnostic Review had been useful for informing other pieces of work they were doing, including the discussions that led to South Africa becoming a pathfinding ${ }^{1}$ country for VAC.

We are able to use this [Diagnostic Review] in our proposal for funding to shape the investment by other funders in South Africa in the area of GBV/ VAC. And when we engaged with global partners we used the Diagnostic Review and root causes study to get support for work in South Africa. We also used the information when doing preparatory work for [the] Stockholm [conference] and in motivating for South Africa to be one of the pathfinder countries; the reports were shared with partners.

(Respondent 1 - development partner)

The seeming openness to sharing the report and its findings helped create connections between government and CSOs and created space for more open conversations about why government interventions had not worked to address VAWC and what was needed to strengthen government response to VAWC.

What was useful was that when it [Diagnostic Review] became public it became the basis of a conversation. And an honest conversation. The Diagnostic Review said tough things and in a way that did not sound blamey. The findings were hard and difficult but did not come across accusatory.

(Respondent 4 - think tank)

The respondent from DPME also indicated how, beyond its specific recommendations, the Diagnostic Review had been used in preparation of the government's next Medium-Term Strategic Framework (MTSF). She, however, was cautious to claim victory in being able to influence the MTSF as the process was not yet complete. 
Another conceptual use was enabling DPME to use evidence to respond to related issues arising. For example, the Diagnostic Review was very important when government had to respond to the Total Shutdown movement:

When \#TotalShutdown happened, we had material to help us respond. The Diagnostic Review shaped the government's input to the GBV summit held in November 2018. We had something to say and used it to push back against what lobbyists might be pushing for using research.

(Respondent 2 - government)

What can we learn from the interventions that were implemented to promote use of the evidence from the Diagnostic Review and the resultant decisions it influenced? Table 6.1 presents use interventions and decisions influenced as stand-alone activities for ease of reading.

It is important to note that, though presented in Table 6.1 as stand-alone interventions, the way that the different use interventions worked to produce evidence use is not linear. In fact, the interventions interacted with one another and one action stimulated another in a snowball effect. The next section shows how these specific use interventions interacted with the wider context and with each other to facilitate uptake of evidence.

\section{Enablers and inhibitors of evidence use in the VAWC sector}

When commenting about barriers to evidence use, most respondents tended to reflect on trends they have observed in the sector more broadly rather than focusing on the Diagnostic Review. Therefore, the following analysis does not limit itself to the Diagnostic Review but includes experiences with other research and evaluation in the VAWC sector. It takes elements from the analytical framework relating to context, taken from Chapter 3. These are summarised in Table 6.2 and elaborated after the table.

\section{The macro-context}

An important barrier to uptake of research and full implementation of research findings that respondents raised and reflected on is the seeming disjuncture between the values of individual public servants and those of researchers. This was seen in contestations around the amendment of the constitution to decriminalise sexual relations between young children, discussions around the right to terminate pregnancy and, more recently, the criminalisation of spanking where religious communities applied for an appeal citing a religious right for parents to chastise their children:

We are a conservative society, but our policies are very liberal. We have tried to impose policy on people who do not want it. We need to work closely with people who have to implement policies. Because if you are 
Table 6.1 Interventions to promote use and their effect

\begin{tabular}{|c|c|}
\hline Intervention & Effect \\
\hline \multicolumn{2}{|l|}{ Elements of the NES } \\
\hline $\begin{array}{l}\text { Technical Working } \\
\text { Group and Evaluation } \\
\text { Steering Committee } \\
\text { comprising key } \\
\text { stakeholders }\end{array}$ & $\begin{array}{l}\text { The interactions in the TWG and ESC facilitated } \\
\text { co-development of evaluation elements, e.g. ToRs, } \\
\text { collaboration and trust between DSD, DPME and } \\
\text { UNICEF. They provided a safe space for meaningful } \\
\text { dialogue. In this space the researchers could gain } \\
\text { understanding of the policy world they are evaluating, and } \\
\text { policy makers could be made more aware of the research } \\
\text { process, inform the process and interrogate findings and } \\
\text { analysis. The ESC was also useful in building consensus on } \\
\text { problem definition. }\end{array}$ \\
\hline Simple evaluation report & $\begin{array}{l}\text { The full evaluation report was } 206 \text { pages long. The } 1 \text {-page, } \\
5 \text {-page and } 25 \text {-page structure used for the summary report } \\
\text { under the NES facilitated accessibility of the findings. }\end{array}$ \\
\hline Management response & $\begin{array}{l}\text { The management response provided a formal mechanism } \\
\text { whereby the different departments had to formally } \\
\text { acknowledge the recommendations. }\end{array}$ \\
\hline Improvement plan & $\begin{array}{l}\text { The improvement plan provided a plan agreed by all } \\
\text { stakeholders for taking forward and institutionalising the } \\
\text { recommendations. }\end{array}$ \\
\hline $\begin{array}{l}\text { Report public on } \\
\text { DPME website }\end{array}$ & $\begin{array}{l}\text { The availability of the report, improvement plan etc. created } \\
\text { transparency and access and increased commitment from } \\
\text { stakeholders. }\end{array}$ \\
\hline
\end{tabular}

\section{Elements outside the NES}

\author{
Knowledge brokering \\ role of departmental \\ M\&E unit
}
Knowledge brokering role of DPME
Process facilitation and relationship management

Internal communication made management and the minister of the department aware of the findings and recommendations and created an opportunity to potentially agree/object to what has been recommended. Formal approval authorises the evaluation unit to hold the department and individual units accountable for implementation of the research findings.

An important role was played by DPME as both a commissioner and knowledge broker in supporting the use of the Diagnostic Review up to two years after completion of the evaluation. This role in this evaluation went beyond the normal role that DPME evaluation directors played.

VAWC is predominantly experienced in black communities. However, lead researchers tend to be white, and this was the case with the Diagnostic Review. This has the potential to create tensions that inhibits uptake of findings. For the Diagnostic Review this was also an issue. The DPME project manager played a relationship management role, sensitising the research team to dynamics they should be aware of, including advising them to add experienced black researchers to the team. A more balanced team was well received and their work better received. 
Table 6.1 (Continued)

\begin{tabular}{|c|c|}
\hline Intervention & Effect \\
\hline $\begin{array}{l}\text { Spaces for ongoing } \\
\text { dialogue in the sector }\end{array}$ & $\begin{array}{l}\text { Presentation of the Diagnostic Review in sectoral spaces } \\
\text { for ongoing intersectoral dialogue (led by CSOs) like the } \\
\text { Dialogue Forum (now called Violence Prevention Forum) } \\
\text { and Soul City Social Lab enabled difficult conversations } \\
\text { between CSOs, government, development partners and } \\
\text { academia about why interventions have not worked } \\
\text { and how they can be strengthened, and strengthening } \\
\text { partnerships between government and CSOs. This built } \\
\text { trust and strengthened relationships which ensured that } \\
\text { the revised PoA and the National Strategic Plan on GBV } \\
\text { were informed by evidence. }\end{array}$ \\
\hline Advocacy by CSOs & $\begin{array}{l}\text { South African CSOs have a long history of advocacy for } \\
\text { policy reforms. Some of the uses of the Diagnostic } \\
\text { Review were influenced by, or enabled by, CSO advocacy. } \\
\text { This includes CSOs in the Violence Prevention Forum } \\
\text { and the Soul City Social Lab and Shukumisa Campaign. }\end{array}$ \\
\hline
\end{tabular}

Table 6.2 Summary of enabling factors and barriers from the context

\begin{tabular}{|c|c|c|}
\hline $\begin{array}{l}\text { Element of the } \\
\text { context }\end{array}$ & Enabling factor & Inhibitor \\
\hline \multirow[t]{2}{*}{ Macro-context } & Progressive legislation & $\begin{array}{l}\text { Conservative values in the } \\
\text { bureaucracy do not match } \\
\text { progressive legislation }\end{array}$ \\
\hline & $\begin{array}{l}\text { Demand from policy } \\
\text { makers for diagnostic } \\
\text { review }\end{array}$ & $\begin{array}{l}\text { Perception that in many cases research } \\
\text { is shaped by researchers not policy } \\
\text { makers and does not answer key } \\
\text { implementation questions like cost }\end{array}$ \\
\hline \multirow[t]{3}{*}{$\begin{array}{l}\text { Intra- and inter- } \\
\text { institutional } \\
\text { linkages }\end{array}$} & $\begin{array}{l}\text { Where these exist, good } \\
\text { relationships between } \\
\text { government and } \\
\text { researchers }\end{array}$ & $\begin{array}{l}\text { Interaction between researchers, } \\
\text { government, NGOs etc. are often } \\
\text { hostile, characterised by serious } \\
\text { mistrust, power misuse, power } \\
\text { dynamics, personality politics etc. }\end{array}$ \\
\hline & $\begin{array}{l}\text { Role of DPME in building } \\
\text { trust and understanding } \\
\text { between supplier and } \\
\text { government users }\end{array}$ & $\begin{array}{l}\text { Competition between departments } \\
\text { limiting consensus in policy, } \\
\text { collaboration and co-delivery of } \\
\text { policy }\end{array}$ \\
\hline & $\begin{array}{l}\text { Multiple engagements } \\
\text { reinforcing messages and } \\
\text { relationships }\end{array}$ & $\begin{array}{l}\text { Organisational silos within and across } \\
\text { departments }\end{array}$ \\
\hline $\begin{array}{l}\text { Organisational } \\
\text { capacity }\end{array}$ & & $\begin{array}{l}\text { Lack of time and capacity to absorb } \\
\text { research }\end{array}$ \\
\hline $\begin{array}{l}\text { Linking } \\
\text { research } \\
\text { and other } \\
\text { evidence }\end{array}$ & $\begin{array}{l}\text { Research processes that } \\
\text { give voice to the lived } \\
\text { experiences of women } \\
\text { and not just the voice of } \\
\text { the researcher }\end{array}$ & $\begin{array}{l}\text { Weakness in facilitating linkages } \\
\text { between research and the } \\
\text { experience of wider stakeholders }\end{array}$ \\
\hline
\end{tabular}


forced to implement a policy you do not believe in and goes against what you believe, who will you blame but the client. We have not been informed by what is going on the ground but what is coming from top down. We have imposed policies on populations who have not had a say on them.

(Respondent 9 - research institute)

Where research seems to be pushing for liberal positions or a position in policy does not accord with the values of those implementing it, the position is less likely to be taken on and does not significantly change the way services are provided. Kahan (2007) referred to this as identity protective cognition. People are more likely to use evidence in ways that are supported by their peer groups than to be guided by the fidelity of the evidence. Shared ideological and cultural commitments are likely to be intertwined with membership of communities (such as church, office, etc.) that furnish individuals with important bases of support. Most individuals will rarely form a contrary position to one held in institutions that provide them with important aspects that define their identity and social support.

The Diagnostic Review did not address any of the contentious issues in the sector. It focused on systems and how the government system was responding to the problem. Though it raised the issue of the beliefs and values of public servants, this was not a central issue of focus. Therefore, it was easier for different sectors and departments to agree on findings and recommendations.

\section{Intra- and inter-institutional linkages}

According to Weyrauch et al. (2016, p. 35),

There are two particular types of relationships that exert significant influence over how knowledge interacts (or not) with policy. One is related to the internal relationships between the government institution and other related government agencies. The second one relates to interaction with relevant users and producers of knowledge who can affect or be affected by policy design and implementation.

In this case we reflect on relationships between government and researchers, and relationships within government.

Relationships between researchers and government or NGOs implementing programmes was cited as an important facilitator/barrier to evidence uptake. Some respondents argued that unrecognised and inadequately addressed trauma is seen in the behaviours of individual decision makers (both in government and NGOs) and in the nature of relations within the sector. Respondents reported that interactions between researchers, government and NGOs, and within government departments, are often hostile, characterised by serious mistrust, power misuse and personality politics hindering evidence-informed policy discussions in the sector. 
Another important issue shaping relations in the sector is race. As already mentioned, researchers tend to be white and public service policy makers and implementers at national level are usually black, and specifically black Africans. This often raises issues of perceived cultural imposition and ideological differences between researchers and public servants or the communities they research.

We (as white people) can't speak any of the African languages. It is seen as disrespectful in many settings; even communities have often raised the issue of race. We often experience people who are openly dismissive because we are white.You walk into a meeting and people look you up and down and comment in another language. You can anticipate that it is unlikely that they will listen to you, they will come back to you with some response about you not understanding the cultural context. Despite indicating our understanding of the culture, they will make some comments that refer to your otherness and your difference. This is fine, I recognise that I am a product of apartheid and that my otherness is an issue.

(Respondent 11 - development specialist)

This played out in the Diagnostic Review and illustrates the importance of internal M\&E units' key knowledge broker role. When KPMG was hired to carry out the work, there were reservations because the lead researcher was a white English woman who had recently relocated to South Africa, and the team was predominately white. There were questions about the ability of the team to understand the experiences of black women and communities. To overcome this issue, the DPME project manager, together with the Chief Director for $M \& E$ at DSD, advised KPMG to diversify their team and sensitised the research team to what is likely to trigger pushback from the ESC. As a result, KPMG added black sector experts to their team. Second, the project manager in DPME managed relations with the ESC, often having discussions outside of the official ESC meetings with senior officials in key departments to allay their fears about the research process or team. Most of the communication to external stakeholders was by DPME and DSD, not the evaluators. By doing this, the relationship between government and researchers was maintained, and despite some of the difficult findings that pointed at failures of government, the evaluation was not rejected by government.

The case study also showed how when a piece of evidence is completed it becomes part of an existing body of knowledge and moves between existing networks of people and institutions. Interviews revealed how often it was existing connections between individuals and reinforcement through different platforms that promoted ongoing conversations that were important enablers of use of the Diagnostic Review. The National Treasury respondent indicated that it was being part of ongoing dialogue with the sector through the CSOled Dialogue Forum (now called the Violence Prevention Forum) that made all these different studies make sense, including the Diagnostic Review. The same 
official was part of a study tour to Uganda to see Ugandan models for violence prevention that had been effective. He stated the following: 'Going on the study tour broadened my perspective on interventions that are available to address violence. I looked at the interventions that are available in Uganda and see what we can learn' (Respondent 3 - government).

This is a good example of how a combination of factors often work together to influence the use of evidence. In this case, participation in an ongoing discussion with CSOs, government and academics and going on a study tour primed the official to be able to receive and use the information. Exposure of this Treasury official made it possible for the DSD's request for additional budget to be supported at a time when government was cutting budgets across the public service. Also, it highlights the importance of spaces for dialogue in evidence use, particularly in a sector where there are high levels of contestation, fragmentation, value-laden issues and so forth. Spaces for dialogue offer opportunities for sense making that can challenge strongly held beliefs, unlike other communication approaches. This can enhance interaction between different stakeholders, foster agreement with research evidence and motivate stakeholders to act on the evidence, key in promoting behaviour change.

Organisational silos and competition between departments was raised as a key challenge in the VAWC sector. VAWC programmes span many different policy domains that are the responsibility of different departments, and the silo mandates create artificial divisions within the VAWC sector that limit information flows. Respondents reported that collaboration is weak in the sector, and there is competition and conflictual relations between departments:

A lot of the decision-making processes in government are based on politics and some form of competition and not on technical issues. That is the issue. It creates huge problems. Competition between departments, units, individuals and even within the same party. People do not get along and the right decisions do not get taken.

(Respondent 7 - independent consultant)

This was also the experience of other respondents who argued that revision of the PoA was hampered by relationship issues between departments.

The fragmentation also happens within departments where it is possible to have different units working on different aspects of VAWC. In DSD, for example, there is the Children's Unit which works primarily through the lens of the child protection system; the Victim Empowerment Programme (VEP) unit is mostly guided by VEP policy; the Family Unit's work is shaped by the White Paper on Families; then there is the Social Crime Prevention Unit, amongst others. A respondent spoke of contestations within DSD where there was no agreement on some policy issues between the Children's Unit and the VEP Unit:

During the revision of the PoA, theVEP chief director left the process. This created a power crisis. The two directorates are not working well together, 
not taking decisions and not engaging with materials that are developed for the project.

(Respondent $2-$ consultant)

The fact that VAWC is spread between so many units has been a problem. No one takes full responsibility for it in the department. You cannot hold any one unit for the improvement plan. I used to ask progress from one unit, and one day I was just told to go ask another unit. And that unit has not been responsive.

(Respondent 14 - government)

The different units in departments dealing with VAWC tend to relate to their subsector and the research that is produced in that subsector. This deepens policy fragmentation in the sector, as researchers in different subsectors are likely to push for certain reforms without being cognisant of how those reforms affect the entire policy area and therefore the achievement of broader policy outcomes (Gould et al., 2017). The ESC provided a platform to facilitate information sharing during the research process, and attempted to overcome these fragmentations.

Balancing different ways of knowing (grassroots knowledge

and research evidence) in policy

Participants spoke about how despite instrumental implementation of the Diagnostic Review's recommendations, there were difficulties in balancing knowledge from empirical evidence with that from communities/CSOs that were consulted during the review of the PoA and planning the presidential GBV summit. Research was seen in some of the discussions as an elite indulgence which does not always represent the needs of survivors. Survivors of violence wanted certain actions (e.g. harsher punishment of perpetrators), which in some cases empirical evidence showed was not effective to address the problem.

\section{Conclusions and lessons}

\section{How did the context and intervention influence the use of evidence?}

A realist analysis suggests that in different contexts, interventions will result in varying outcomes (see Chapter 1). From a realist perspective, change cannot be solely attributed to the nature of an intervention as there are underlying causes of change that may not be directly observable (Pawson et al., 2005). Interventions (I) require mechanisms $(\mathrm{M})$ which connect programmes to their outcomes $(\mathrm{O})$ within certain contexts $(\mathrm{C})$. In this case study, the intervention included an evidence-generation process (an evaluation) and interventions to promote use (e.g. communications), which influenced certain behavioural 
mechanisms (agreement, access to information, building trust, amongst others) and resulted in certain use outcomes (how the evidence influenced policy and practice). Understanding which mechanisms work within which context can help us understand conditions that increase the likelihood of research utilisation and therefore we can be better placed to reproduce these. Here we added to the realist Context-Mechanism-Outcome configuration, Interventions for evidence use.

In this case study we observe a number of interventions and mechanisms that appear to facilitate use of evidence (building on the analytical framework in Chapter 2):

1 In the context of interventions crossing organisational silos, the following are essential:

- The formalised involvement of different organisations and stakeholders in the evidence-generation process (evidence generation). The participation of departments in the research process and on structures like the steering committee/IMC TTT was important to legitimise the research process and the outcomes. When departments pushed against the findings or recommendations on the grounds that their departments were not consulted, DSD and DPME could remind the departments of their participation in the research process.

- Dissemination of findings with government formalised structures for coordination is essential. In this case study, these were the clusters and the IMC (inter-ministerial committee), which allowed different departments to interrogate the research and its implications for their departments (use intervention), in some cases suggesting changes to how the recommendation should be responded to.

2 In a sector where people hold strong opposing beliefs and where there is a history of conflict, oppression and subordination on the basis of race (or any other construct) (context), the following are very important:

- The representativity of the evidence-generation team (evidence generation);

- Wide dissemination of evidence led by government (use intervention);

- Knowledge brokers that can facilitate mutual understanding and trust (use intervention);

- Promotion of spaces for meaningful dialogue (use intervention), which can promote agreement, mutual understanding and trust (change mechanisms).

3 In a context where there is poor inter-sector communication and relations, introducing the Diagnostic Review (government piece of evidence) into use interventions in the wider policy ecosystem was an important facilitator of much-needed honest discussion about how to strengthen the country's response to VAWC and therefore the use of the evidence. Examples of 
interventions included the government-led study tour to Uganda, the Violence Prevention Forum (CSO-led), the Social Lab (CSO-led) and Shelter Movement work (CSO-led), through the knowledge brokering role of government (use intervention).

4 In the context of well-established and vibrant CSOs with a history of community mobilisation and policy reform advocacy and a democratic government that embraces participation in political processes, pressure from grassroots CSOs pushed government to implement some of the recommendations.

\section{Lessons around use of evidence in the VAWC sector}

The case study shows how, though use interventions are critical to facilitate use of evidence, policy making and implementation is a long process that is highly contested and without a clear beginning or end. Therefore use interventions enable change in a nonlinear, and sometimes unpredictable, chain of reactions. Knowledge brokering is an important facilitator of evidence use; however, this process has to be built into the research process. This is because policy decisions are made at different stages of policy development - problem identification and analysis, options analysis, choice of intervention, implementation and M\&E. It is important therefore to appreciate that the power to shape policy shifts between different stakeholders through the policy process. We have also shown how the contestation and power shifts not only happen between government and NGOs but also within government institutions, particularly in intersectoral policies addressing complex social problems. Government is not homogenous and neither are departments. Within departments, units can have different views on policy and it is possible to have contestations within departments as well as between departments.

Evidence uptake is a continuous process that happens both during and after the research process. If space is created for cross-sectoral discussions during the evaluation process, it can offer opportunity to build consensus on contentious policy issues.

We conclude with some lessons.

Research processes need to overcome the impact of strongly held values, beliefs and norms

In a sector like VAWC with strongly held values, beliefs and norms, evidence use is more than a technical endeavour. These values can be held by individual policy makers, politicians and staff in organisations, making it difficult for research that challenges these values to influence policy and transform the way policy and programmes work. Researchers and evaluators in the sector are therefore not only involved in the process of producing knowledge for policy making, but they are engaged in a process that questions societal values, beliefs 
and norms. Opening the research process to interrogation by people who hold different positions in spaces where they can interact with one another and with the research process can open research to take in the different perspectives, enriching the research and strengthening advocacy possibilities.

Safe spaces where meaningful conversations can be held are critical, as are the skills to facilitate such conversations. Steering committees, when managed well, can create safe spaces for different views to be debated during the research process, thus informing analysis, conclusions and recommendations from research. But these spaces for dialogue can also be provided for outside of the research process. External stakeholders such as think tanks and CSOs have key roles to play in this regard, as this case study has demonstrated.

\section{The composition of the research team matters}

Given South Africa's history, VAWC disproportionately affects black communities which are often the intended beneficiaries of programmes targeting poverty-related issues, and are also often the objects/subjects of research. Representivity in research teams can address the sense of 'othering' of communities. Representivity, however, is not just about including researchers of different races, gender or sexual orientation (or whatever social categorisation is important in a specific context). It is also about representation of different world views, ideologies and experiences that relate to the populations being studied and those that the research process aims to influence. Such an approach to setting up research teams can enrich research processes and make researchers sensitive and responsive to issues that might make it difficult for certain people to receive the messages from the research.

\section{Wider lessons}

\section{Importance of government internal capacity for research/evaluation and knowledge brokering}

Government internal evaluation and research capacity is important for effective evidence use. Evaluation/research units in departments need to have the capacity to work with policy makers and implementers as knowledge brokers to develop evidence agendas, have systems to access research carried out by institutions outside of government and have the capacity to make sense of external research and to advise policy makers. They need to create spaces for dialogue between their departments and external researchers. Where research is commissioned, these units still need to have the capacity to shape and guide the research process to ensure it remains relevant and can be used effectively. Where government has strong evaluation/research capacity, it is better placed to shape the research agenda, ask the right policy questions and guide the production of evidence to ensure that it responds to policy needs. 
Complexity of internal government policy-making processes

Some of the challenges with evidence use related to how policy making unfolds in the South African government. Most policy discussions are not open to participation by non-government stakeholders. They happen between and within departments and public entities, in management fora, at clusters, Cabinet and so forth, and consultation with wider stakeholders often only happens when this process is completed. It can be difficult for a policy maker to push an idea through these different government structures simply because it is evident in research, particularly if it challenges dominant values and views. Government needs to be more open to including wider views earlier on in processes and individual policy makers need to be supported through what can be lengthy policy processes.

Evidence needs to be used for the underlying meaning, not just compliance with recommendations

This case study shows that it is possible for departments to implement recommendations and therefore tick the box of instrumental use without this affecting the wider meaning underlying the policy, and so actual policy content and implementation. Organisations may use research evidence to make minor changes to policy and programmes, but not necessarily to transform policy approaches. In the Diagnostic Review, the respondents acknowledged that the recommendations that were implemented were the least controversial and therefore easier to implement. The evidence-informed decision-making sector needs a better understanding of how to support decision makers and institutions and develop means of measuring evidence use that overcome this challenge.

\section{And finally}

This chapter has focused on an evaluation in a complex sector, with inter- and intra-organisational dependencies and rivalries, and strongly held and differing values which often differ between policy makers, and between policy makers and researchers. It highlights the mistrust and miscommunication between many researchers and policy makers and how this had to be mediated. The chapter showcases an evaluation conducted carefully and sensitively, paying a lot of attention to process and not just product which has led to significant use, both instrumentally and conceptually. The evaluation was helped by an established national evaluation system, formalising many of the elements likely to promote use. The focus on systems which can build co-ownership is critical. We also see the importance of facilitating meaningful dialogue within departments, across departments, and with wider stakeholders - facilitation skills which are rare in government. The latter is an area where more work is needed to see how to build the skills and systems which can promote such dialogue, can build trust 
and openness to evidence, and can help to build changes in understanding, in motivation to do things differently and in the capability to do so.

\section{Note}

1 Since its launch in July of 2016, the Global Partnership to EndViolence Against Children has promoted the concept of pathfinding, which aims to raise awareness, stimulate leadership commitment, galvanise action, and establish a standard of national violence prevention throughout the world (www.end-violence.org/pathfinding-countries).

\section{References}

Ademiluka, S.O. 2018. Patriarchy and women abuse: Perspectives from Ancient Israel and Africa. Old Testament Essays, 31(2), 339-362.

Amisi, M.M. and Vawda, A. 2017. Strengthening democratic governance in the building of integrated human settlements through evaluations. In Podems, D. (ed.), Democratic evaluation and democracy: Exploring the reality. Charlotte: Information Age Publishing, pp. 127-138.

Barberton, C., Abdoll, C., Ragwala, L., Budlender, D. and Mohamed, Z. 2018. Performance and expenditure review: Cost implications of funding for NPOs following the Nawongo court judgements. Government Technical Advisory Centre, National Treasury, Cornerstone Economic Research. Retrieved from www.gtac.gov.za/perdetail/Cost $\% 20$ implications $\% 20$ of $\% 20$ funding $\% 20$ NPOs $\% 20$ following $\% 20$ the $\% 20$ NAWONGO $\% 20$ court $\% 20$ judgements.pdf

Chipkin,I.and Meny-Gibert,S.2011. Why the past matters:History of the publicservice in SouthAfrica. Retrieved from https://pari.org.za/past-matters-histories-public-service-south-africa/

DPME. 2017. The evaluation of the non-profit regulatory system. Department of Planning, Monitoring and Evaluation and the Department of Social Development. Unpublished report.

DPME and DSD. 2016. Diagnostic review of the state response to violence against women and children. Department of Planning, Monitoring and Evaluation, and the Department of Social Development. Retrieved from https://evaluations.dpme.gov.za/images/gallery/ DPME\%20-\%20VAWC.pdf

Gender Links and The Medical Research Council.2010. The war@home: Findings of the GBV prevalence study in Gauteng, Western Cape, KwaZulu Natal and Limpopo Provinces of South Africa. Retrieved from https://genderlinks.org.za/programme-web-menu/publications/ the-warhome-findings-of-the-gbv-prevalence-study-in-south-africa-2012-11-25/

Gould, C., Mufamadi, D., Amisi, M.M., Dartnall, E., Moruane, S., Abdoll, C., Connors, J., Naicker, S., Shai, N., Malek, E., Rezant, B., Edelstein, I., Mabunda, A., Mayet,Y., Frost, K., Dippenaar, W., Kader, Z., Iewaks, A. and Moeketsi, J. 2019. What will it take to prevent interpersonal violence in South Africa? Institute for Security Studies (ISS) policy brief, Pretoria. Retrieved from https://issafrica.org/research/policy-brief/what-will-it-take-to-preventinterpersonal-violence-in-south-africa

Gould, C., Mufamadi, D., Hsiao, C. and Amisi, M.M. 2017. Preventing violence in South Africa: From policing to prevention. Institute for Security Studies (ISS) policy brief, Pretoria. Retrieved from https://issafrica.org/research/policy-brief/reducing-violence-insouth-africa-from-policing-to-prevention

Hall, K. and Mokomane, Z. 2018. The shape of children's families and households: A demographic overview. In Hall, K., Richter, L., Mokomane, Z. and Lake, L. (eds.), Children, families and the state. South African Child Gauge, Children's Institute, University of Cape Town. Retrieved from www.ci.uct.ac.za/sites/default/files/image_tool/images/367/ 
114 Matodzi M. Amisi et al.

Child_Gauge/South_African_Child_Gauge_2018/Chapters/the_shape_of_childrens_ families_and_households.pdf

Kahan, D.M. 2007. Culture and identity-protective cognition: Explaining the white male effect in risk perception. Faculty Scholarship Series. 101. Retrieved from https://digitalcommons.law. yale.edu/fss_papers/101

Lamb, G. and Warton, G. 2011. Why is crime in South Africa so violent? A rapid review. Programme to Promote Pro Poor Policy Development, Pretoria. Retrieved from www. psppdknowledgerepository.org/search/adsearch/send/62-rapid-evidence-reviews/275why-is-crime-in-south-africa-so-violent-a-rapid-review

Meer, F. 2016. Women in the apartheid society. Retrieved from www.sahistory.org.za/archive/ women-apartheid-society-fatima-meer-0

Pawson, R., Greenhalgh, T., Harvey, G. and Walshe, K. 2005. Realist review: A new method of systematic review designed for complex policy interventions. Journal of Health Services Research E Policy, 10(1), 21-34. https://doi.org/10.1258/1355819054308530.

Rauch, J. 2000. The national crime prevention strategy. Retrieved from www.csvr.org.za/docs/ crime/1996nationalcrime.pdf

Statistics South Africa. 2016. Community survey 2016-in brief. Retrieved from http://cs2016. statssa.gov.za/wp-content/uploads/2017/07/CS-in-brief-14-07-2017-with-cover_1.pdf

Ward, C.L., Artz, L., Leoschut, L., Kassanjee, R. and Burton, P. 2018. Sexual violence against children in South Africa: A nationally representative cross-sectional study of prevalence and correlates. Lancet Global Health, 6, e460-e468. Retrieved from www.thelancet.com/ action $/$ showPdf?pii=S2214-109X\%2818\%2930060-3

Weyrauch,V., Echt, L. and Suliman, S. 2016. Knowledge into policy: Going beyond 'Context matters'. Retrieved from www.inasp.info/sites/default/files/2018-04/Going\%20beyond\%20 context $\% 20$ matters $\% 20 \%$ E2\%80\%93\%20framework.pdf

World Bank. 2018. Overcoming poverty and inequality in South Africa: Assessment of drivers, constraints and opportunities. Retrieved from http://documents.worldbank.org/curated/ en/530481521735906534/pdf/124521-REV-OUO-South-Africa-Poverty-and-Ine quality-Assessment-Report-2018-FINAL-WEB.pdf 